\title{
Spiral Enteroscopy Value for the Celiac Disease Diagnosis and Management
}

\author{
Ofelia Mosteanu ${ }^{1,2}$, Teodora Atena Pop ${ }^{1,2, *}$, Adina Hadade ${ }^{1,3}$, Marcel Tantau ${ }^{1,2}$ \\ 1“Iuliu Hatieganu” University of Medicine and Pharmacy Cluj-Napoca, Romania \\ ${ }^{2}$ Department of Gastroenterology, Regional Institute of Gastroenterology and Hepatology "Prof.Dr.O.Fodor” Cluj-Napoca, Romania \\ ${ }^{3}$ Department of Anesthesiology, Regional Institute of Gastroenterology and Hepatology “Prof.Dr.O.Fodor” Cluj-Napoca, Romania \\ *Corresponding author: teodorapop@gmail.com
}

Received February 18, 2014; Revised February 20, 2014; Accepted February 21, 2014

\begin{abstract}
Recently, spiral enteroscopy (SE) has been promoted as an alternative technique to obtain deep access into the small bowel. Using this technique, one may assess the distal small bowel mucosal alterations or monitor the developing of complications in celiac disease (CD) patients. Thus, SE value derives from the possibility of tissue sampling and consequently, modifying further the patient's management. Spiral enteroscopy should be reserved for patients who are developing complications during celiac disease follow-up. It is not advisable to perform enteroscopy as the initial work-up of suspected CD patients.
\end{abstract}

Keywords: spiral enteroscopy, celiac disease, enteropathy associated T-cell lymphoma

Cite This Article: Ofelia Mosteanu, Teodora Atena Pop, Adina Hadade, and Marcel Tantau, "Spiral Enteroscopy Value for the Celiac Disease Diagnosis and Management." International Journal of Celiac Disease, vol. 2, no. 1 (2014): 27-30. doi: 10.12691/ijcd-2-1-8.

\section{Introduction}

Celiac disease (CD) is a chronic, gluten-induced autoimmune enteropathy that manifests itself with a range of clinical symptoms in genetically susceptible subjects. The patients may present with the typical clinical symptoms of abdominal pain, weight loss, diarrhoea and malabsorption or in a rather atypical way, with heartburn and irritable bowel syndrome-like symptoms or be clinically silent.

The gold standard of diagnosis is villous atrophy on duodenal biopsy and the modified Marsh classification is used for classifying the severity of villous atrophy on biopsy, although, recently, there are doubts regarding the practical usefulness of the Oberhuber modifications $[1,2]$.

The mucosal changes associated with celiac disease can be patchy and this patchy villous atrophy or disease present a significant sampling error that leads to the possibility of missing the diagnosis. Also, recently it has been shown that total villous atrophy significantly increases in the distal small bowel, up to $11.1 \%$ having the entire small bowel involved [3,4]. Any delay in the diagnosis can be detrimental because the course of untreated celiac disease is not always benign.

\section{Indication for Spiral Enteroscopy in Celiac Disease.}

The possibility to investigate the small bowel using video capsule endoscopy (VCE) and device-assisted enteroscopy (single or double ballon assisted enteroscopy - DBE; spiral enteroscopy -SE) have accelerated the accurate diagnosis of coeliac disease and its complications such as refractory coeliac disease, enteropathy associated T-cell lymphoma (EATL) and small bowel adenocarcinoma.

The deep enteroscopy role in diagnosis celiac disease complications has been mostly studied using double ballon enteroscopy (DBE), with only a few studies using single ballon enteroscopy or spiral enteroscopy, also, these studies being limited by operators expertise and the number of patients involved.

Spiral Enteroscopy is a new technique for examining the small bowel which is pleated by a special over tube (Endo-Ease Discovery SB) that slides an enteroscope (Olympus enteroscope SIF Q180). Antegrade aproach helps to advance compatible enteroscopes beyond the ligament of Treitz, allowing the spiral to pleat the small bowel in a rapid and controlled manner [5].

Spiral enteroscopy can achieve deep small-bowel intubation in a relatively short time [5] and in patients carefully selected and with clear indications.

Indication for performing spiral enteroscopy in celiac disease patients should be considered in those with clinical, VCE or radiological features suggestive of small bowel stricture or malignancy, thus biopsy may be needed for precise diagnosis, particularly when clinical suspicion persists despite a negative VCE study [6,7]. VCE can be considered as a screening tool, particularly as an aid in directing the approach of enteroscopy and increasing diagnostic yield [8]. In suspected cases of intestinal obstruction it may be preferable to proceed directly to deep enteroscopy due to the risk of VCE retention. 
Endoscopic markers of CD are as follows: a reduction or absence of duodenal folds (Figure 1 and Figure 2); scalloping (Figure 4 and Figure 5), which is a notched appearance of the duodenal folds; visible submucosal vasculature; a mucosal mosaic pattern (Figure 3), looking micronodular or cobblestone due to the mucosal fissures.

Novel methods of enhanced endoscopic imaging (narrow band imaging or magnification endoscopy) do not add much to the diagnosis accuracy, but can guide the biopsies at the affected spots (Figure 3A and Figure 3B).

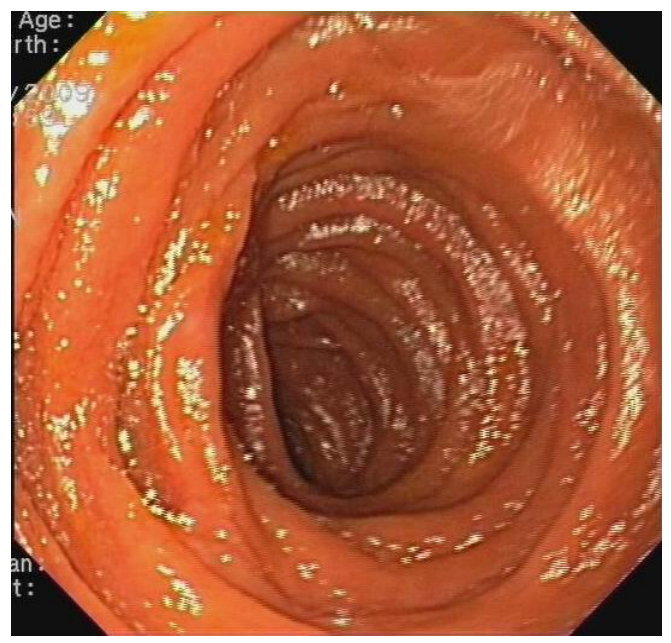

Figure 1. Normal mucosal and circular folds - jejunum

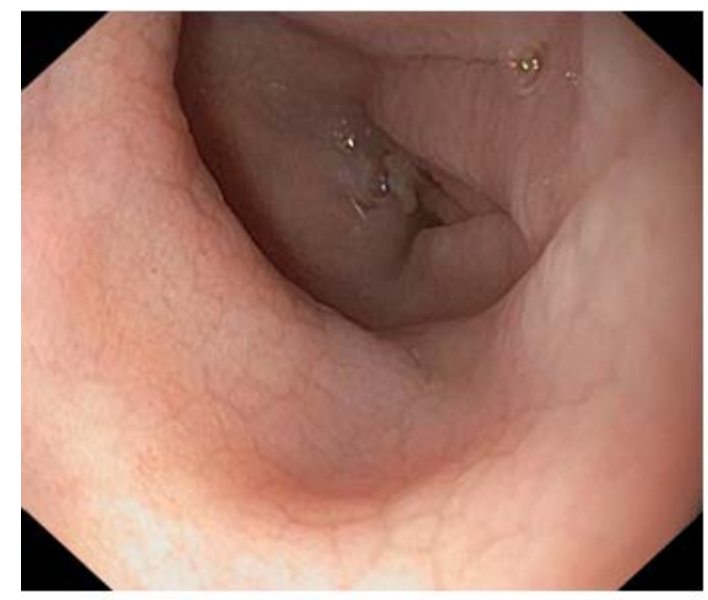

A

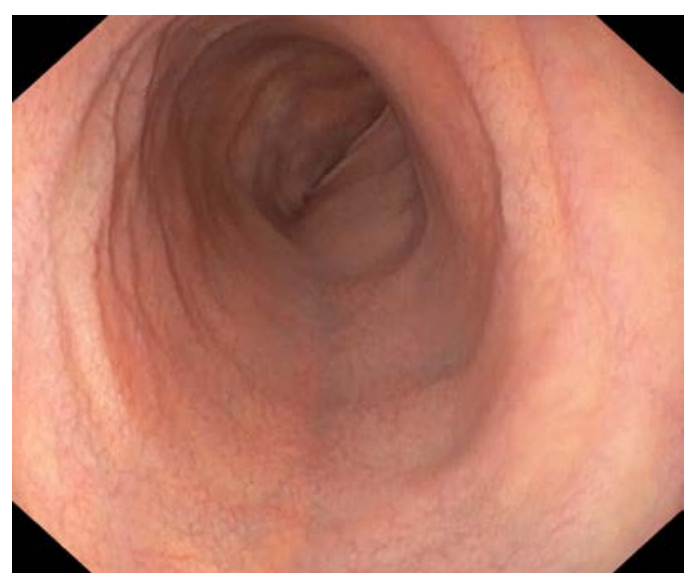

Figure 2. Refractory celiac disease - reduction of jejunal mucosal folds

Enteroscopy should not be considered for the first diagnosis of CD patients, although can detect changes of the small bowel mucosa in up to $17 \%$ of cases with prior negative histology [9]. Being an invasive technique, its role is very important in patients with $\mathrm{CD}$ who fail to response on a gluten free diet (GFD); in CD patients with alarm symptoms (weight loss, abdominal pain, diarrhea, or anemia; $\mathrm{CD}$ patients with history, clinical findings or imaging tests are suggestive of small bowel stenosis or small bowel malignancy; CD patients with VCE findings suggestive of ulcerative jejunitis, EATL, or small bowel adenocarcinoma $[10,11]$.

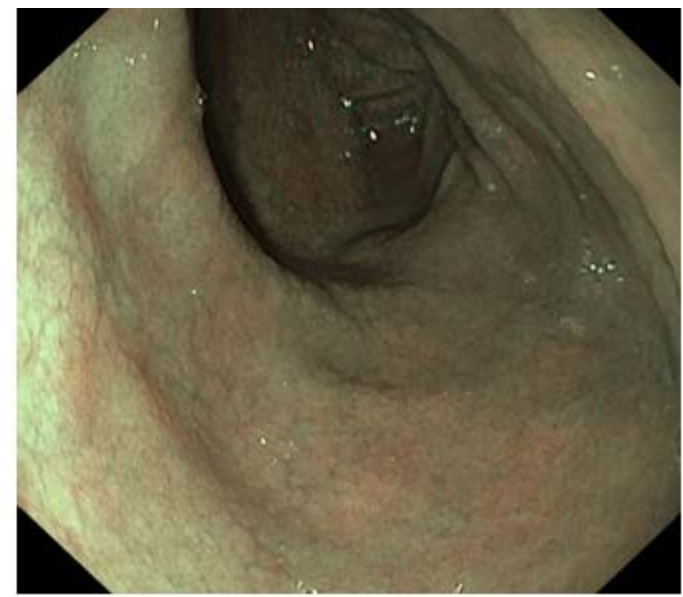

B

Figure 3. A Mosaic pattern - jejunum; B Narrow band imaging - slightly enhancement of the nodular mucosal pattern

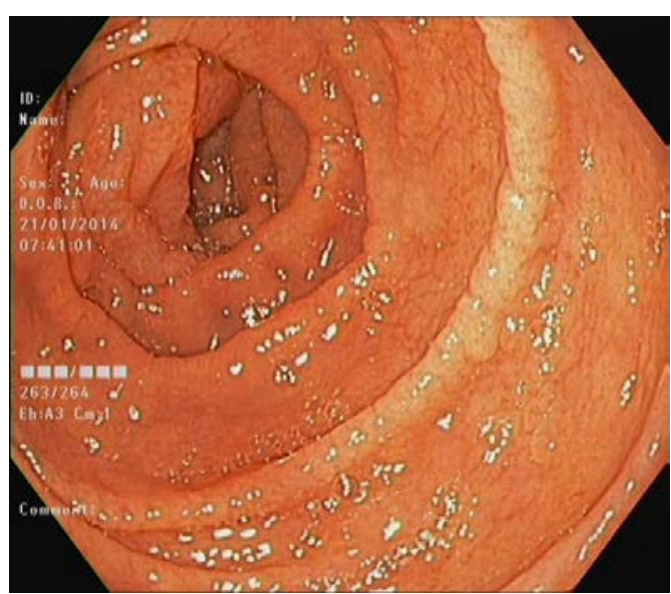

Figure 4. Scalloping of the jejunal folds

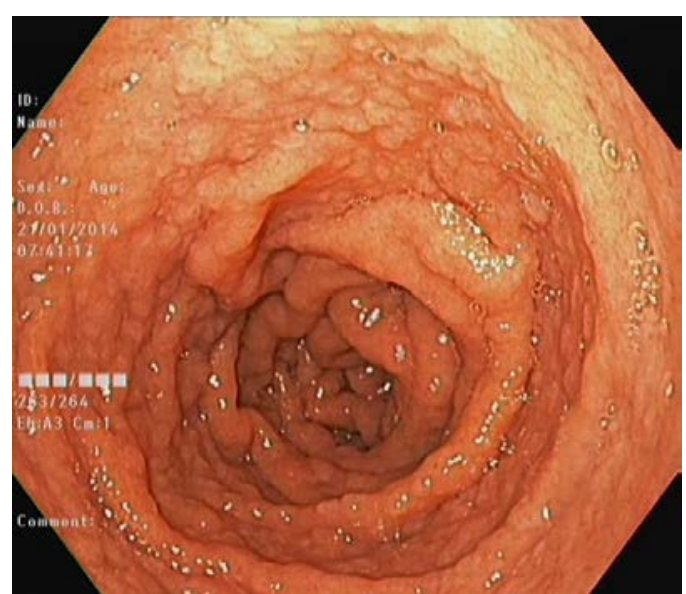

Figure 5. Scalloping of the folds and nodular mucosal pattern - jejunum 
Ulcerative jejunitis (Figure 6) is one of the most severe complication in celiac disease patients, being considered nowadays as a premalignant condition [12]. Its endoscopic appearance can be easily confounded with EATL during VCE, thus biopsy may be needed for accurate diagnosis and further management.

Small bowel involvement with EATL is usually multifocal and primarily affects the jejunum and proximal ileum (Figure 7). Given the proximal predominance of EATL, it is therefore generally advisable to begin with an antegrade approach while performing spiral enteroscopy in complicated CD.

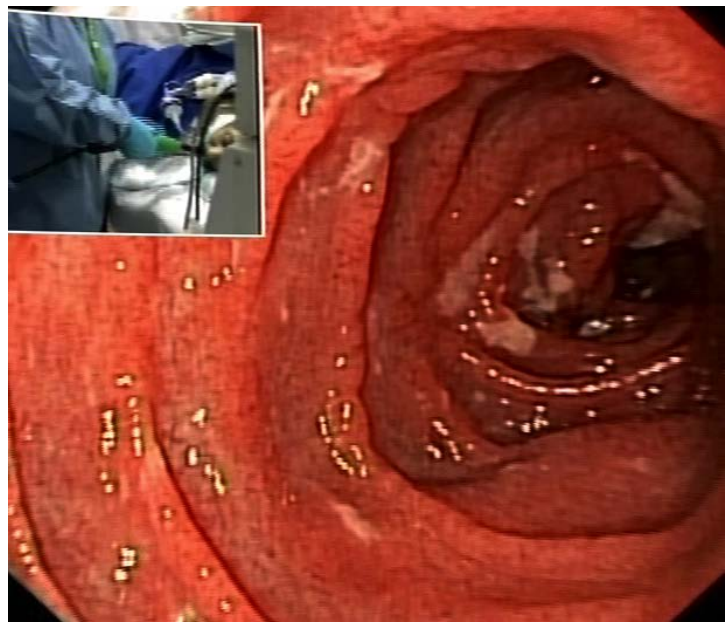

Figure 6. Multiple jejunal ulcerations in the presence of villous atrophy and scalloping of the folds in a 52 years old female patient with CD, partially adherent to GFD

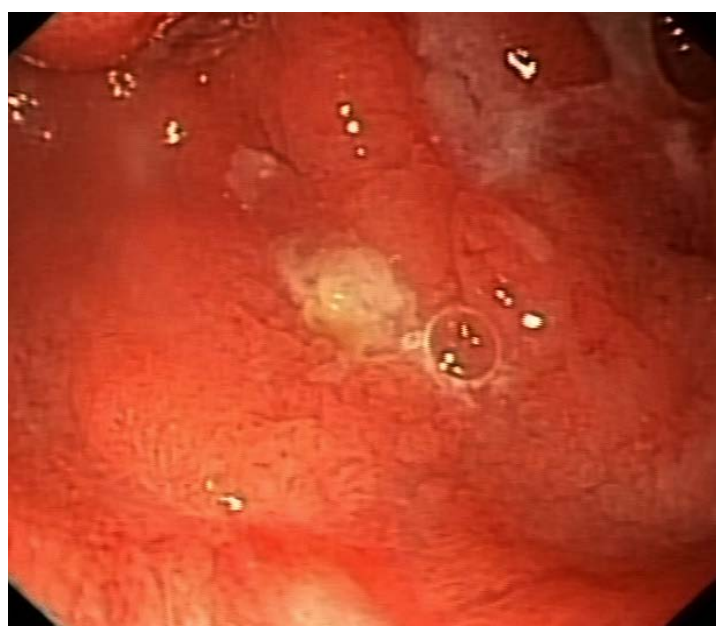

Figure 7. Slightly protruding mass with central ulceration in a refractory celiac disease patient - jejunal EATL

\section{Safety}

Due to the rotating movement, SE may cause significant traction on the mesentery root with potential impairment of the vascular supply. One study performed in an animal model assessed laparoscopically the intraperitoneal cavity after SE and DBE; ecchymosis were found in both cases, with a peritoneal tear in one of the animals subjected to SE [13] In our patients we noticed superficial mucosal lacerations at the level of Treitz ligament and pylorus; also, our patients complained of sore throat. The literature showed that these minor complications are comparable to similar DBE studies' results [14]. The slipping of the scope during therapeutic interventions is decreased due to the stability of the over tube in the small bowel, thus, increasing the safety in comparison to balloon-assisted enteroscopy. The perforation rate ranges between $0 \%$ [15] to $0.34 \%$ [16].

\section{Conclusions}

Understanding the value, role, and timing of proceeding with spiral enteroscopy in the CD patients assessment is of paramount importance. Spiral enteroscopy should be reserved for patients who are developing complications during follow-up. It is not advisable to perform enteroscopy as the initial work-up of suspected CD patients. We are certain that spiral enteroscopy role in the work up of celiac disease will continue to evolve.

\section{Conflicts of Interest}

none.

\section{References}

[1] Corazza, G., Villanacci, V., “Coeliac disease”, J Clin Pathol,. 58(6). 573-574. Jun 2005.

[2] Marsh, N.M., “Another Milestone Passed”, International Journal of Celiac Disease, 1(1). 1-2. 2013.

[3] Ravelli, A., Bolognini, S., Gambarotti, M., Villanacci, V., "Variability of histologic lesions in relation to biopsy site in gluten-sensitive enteropathy”, Am J Gastroenterol, 100(1), 177185, Jan 2005

[4] Rondonotti, E., Spada, C., Cave, D., Pennazio, M., Riccioni, M.E., De Vitis, I., Schneider, D., Sprujevnik, T., Villa, F., Langelier, J., Arrigoni, A., Costamagna, G., de Franchis, R., "Video capsule enteroscopy in the diagnosis of celiac disease: a multicenter study", Am J Gastroenterol, 102(8): 1624-1631, Aug 2007.

[5] Akerman, P.A., Agrawal, D., Cantero, D., Pangtay, J., “Spiral enteroscopy with the new DSB overtube: a novel technique for deep peroral small-bowel intubation”, Endoscopy, 40(12), 974978, Dec 2008.

[6] Tomba, C., Elli, L., Bardella, M.T., Soncini, M., Contiero, P., Roncoroni, L., Locatelli, M., Conte, D., «Enteroscopy for the early detection of small bowel tumours in at-risk celiac patients”, Dig Liver Dis, in press, Jan 2014.

[7] Van Weyenberg, S. J. B., S.V.A. Jarbandhan, S.V.A., Mulder, C.J.J., Jacobs, M.A.J.M., "Double Balloon Endoscopy in Celiac Disease”, Techniques in Gastrointestinal Endoscopy, 10(2), 87-93; Apr 2008.

[8] Kurien, M., Evans, K.E., Aziz, I., Sidhu, R., Drew, K., Rogers, T.L., McAlindon, M.E., Sanders, D.S., "Capsule endoscopy in adult celiac disease: a potential role in equivocal cases of celiac disease?”, Gastrointest Endosc, 77(2), 227-232, Feb 2013.

[9] Kav, T., Sivri, B., "Is enteroscopy necessary for diagnosis of celiac disease?”, World J Gastroenterol, 18(31), 4095-4101, Aug 2012.

[10] Tomba C, Branchi F, Conte D, Bardella M.T., Elli L., "Role of Enteroscopic Techniques in Malignant Complications of Celiac Disease”, International Journal of Celiac Disease, 2(1), 1-3, Jan 2014.

[11] Daveson, A.J., Anderson, R.P., "Small bowel endoscopy and coeliac disease”, Best Pract Res Clin Gastroenterol, 26(3), 315323, Jun 2012.

[12] Ashton-Key, M., Diss, T.C., Pan, L., Du, M.Q., Isaacson, P.G., "Molecular analysis of T-cell clonality in ulcerative jejunitis and enteropathy-associated T-cell lymphoma”, Am J Pathol, 151(2), 493-498, Aug 1997.

[13] Soria, F., Lopez-Albors, O., Morcillo, E., Sarria, R., Carballo, F., Perez-Cuadrado, E., Sanchez, F., Latorre, R., "Experimental laparoscopic evaluation of double balloon versus spiral 
enteroscopy in an animal model”, Dig. Endosc, 23(1), 98, Jan 2011.

[14] Morgan, D., Upchurch, B., Draganov, P'., Binmoeller, K.F Haluszka, O., Jonnalagadda, S., Okolo, P., Grimm, I., Judah, J., Tokar, J., Chiorean, M., "Spiral enteroscopy: prospective US multicenter study in patients with small-bowel disorders", Gastrointest. Endosc, 72(5), 992-998, Nov 2010.
[15] Yamada, A., Watabe, H., Oka, S., Kogure, H., Imagawa, H., Kobayashi, Y., Suzuki, H., Watari, I., Aoyama, T., Isayama, H., Yamaji, Y., Fujishiro, M., Tanaka, S., Koike, K., "Feasibility of spiral enteroscopy in Japanese patients: study in two tertiary hospitals”, Dig Endosc, 25(4), 406-411, Jul 2013.

[16] Akerman, P.A., Cantero, D., "Severe complications of spiral enteroscopy in the first 1750 patients”, Gastrointest Endosc, 69, AB127, 2009. 